\title{
Improving Chronic Kidney Disease Management Using Wagner's Model for Chronic Care
}

\author{
Laura Zuccaro, BHSc ${ }^{1}$ \\ ${ }^{1}$ Faculty of Medicine, University of Ottawa
}

A B STRACT

With an aging population, chronic disease will place an increasing burden on the health care system. Consequently, the Canadian health care system needs to implement systemic changes to manage chronic disease effectively. This paper applies the six basic elements for improving chronic care found in Wagner's Chronic Care Model (CCM) to the management of chronic kidney disease. A fictional patient, Paul, is used to demonstrate the usefulness of this model in managing chronic diseases at a systemic and individual level.

\section{RÉ S U É}

Avec une population vieillissante, les maladies chroniques imposeront un fardeau de plus en plus lourd sur le système de soins de santé canadien. Par conséquent, il faudra mettre en œuvre des changements systémiques pour gérer efficacement les maladies chroniques. Cet article applique les six piliers de base pour l'amélioration des soins chroniques, trouvés dans le modèle des soins chroniques de Wagner, à la gestion de la maladie rénale chronique. Un patient fictif, Paul, est utilisé pour démontrer l'utilité de ce modèle dans la gestion des maladies chroniques à un niveau systémique et individuel.

\section{INTRODUCTION}

Paul is a 45-year-old patient in your family medicine practice who you recently diagnosed with polycystic kidney disease (PKD), a genetic condition that leads to kidney cyst formation. There is no cure for PKD, and Paul's two teenage daughters are also at risk. As a result, Paul will need long-term care for chronic kidney disease. Chronic kidney disease (CKD) is characterized by a progressive and irreversible insult to kidney function. Fluids, electrolytes, and wastes build up as kidney function declines, causing symptoms such as fatigue, nausea, and confusion [reference]. Although there is no cure for CKD, there are strategies to delay the need for renal replacement therapy (RRT), which includes dialysis or transplantation [1]. Management of CKD is multifaceted, involving medications, diet, lifestyle changes, and patient education, with the ultimate goal of slowing the progression of CKD and improving quality of life $[1,2]$.

With the aging Canadian population, the increasing incidence of chronic disease puts a strain on health care delivery [3]. Diabetes and hypertension, the two most common etiologies of CKD, are becoming more common with the aging population [1]. If CKD is not properly managed, it can lead to many complications, such as cardiovascular disease, malnutrition, hormonal imbalance,

Keywords: CKD; chronic kidney disease; CCM; Chronic Care Model; Wagner and bone disease. These complications can decrease a patient's quality of life, lead to dialysis or kidney transplant, and increase long-term health care spending [1]. The increasing incidence of CKD requires effective management solutions to prevent an overwhelming public health burden. For example, multidisciplinary teams are critical in the management of chronic disease, and, in regards to CKD, they may slow the rate of decline in renal function [2]. In one study, CKD care programs reduced the probability of emergency dialysis and hospitalization and lowered medical costs [2]. One similar care program that practicing physicians can implement is Wagner's Chronic Care Model.

Wagner's Chronic Care Model (CCM) outlines six basic elements for improving chronic care [4]. First, the CCM requires a delivery system with well-defined team members, planned visits, regular follow-up, and case management. Next, the organization of healthcare involves supporting improvement strategies, systematic handling of problems, incentives based on quality of care, and care coordination agreements. Embedding evidence-based guidelines into clinical practice, integrating specialists and primary care, and sharing information with patients are crucial for decision support. Next, clinical information systems should provide reminders, share information with providers and patients, facilitate care planning, and monitor performance. Encouraging patient participation in programs, forming partnerships with community organizations, and advocating for policies to improve 
care addresses community resources and policies. Lastly, the healthcare system needs to emphasize patients' central role in their own care by using self-management support strategies and resources [3-5]. Both an informed and active patient and a prepared and proactive team must embrace these elements to ensure productive interactions and shared care planning $[4,5]$. The components of the CCM are demonstrated in Figure 1. Through Paul's mock case scenario, this paper will demonstrate how each element of the CCM contributes to an effective model in managing chronic kidney disease.

\section{HEALTH SYSTEMS}

\section{Delivery System Design}

After a diagnosis of CKD, patients are more likely to return to their family physician for initial follow-up than see a nephrologist [6]. Additionally, as part of the multidisciplinary team, family physicians are encouraged to actively manage CKD prior to referral to nephrology, as it improves patient outcomes by avoiding missed opportunities for early treatment [6]. As the family doctor in the mock scenario, you begin Paul on a course of ACE inhibitors to lower his blood pressure and begin monitoring his kidney function. However, research demonstrates that family physicians do not have enough time to deliver the recommended services for chronic disease management [7]. These clinics utilize a multidisciplinary team to provide the full spectrum of CKD care, including patient education and self-management, in accordance with the CCM [8].

Two months after his diagnosis, Paul visits the CKD clinic and is introduced to the team. Paul's case manager is a trained Nurse Practitioner who will meet with him regularly to decide which areas of the clinic he would need to access. Paul's team also includes a dietician, a pharmacist to review medications and monitor blood work, a social worker to help address medical expenses, a counsellor, and a nurse to help Paul set lifestyle goals. A nephrologist will meet with Paul on regularly scheduled intervals to manage his kidney disease. Finally, office assistants will manage administrative capacities and ensure operations run smoothly. Paul leaves his first meeting overwhelmed with information, but motivated to be an active team member. All the clinic's instructions and roles are given to Paul in a prepared information package for him and his family to review at their leisure. When Paul returns to the CKD clinic for a second appointment, the team creates a long-term care plan with Paul and forwards it to you, his family physician. At scheduled follow-up visits, Paul meets with various members of the team based on his needs. As Paul begins his journey at the CKD clinic, you continue to monitor his health, while closely following his daughters for any sign of PKD. Paul's daughters may be referred to a medical geneticist if they are interested in screening for PKD at a later date.

\section{Organization of Healthcare}

To manage Paul, healthcare organization involves monetary government support; evidence-based CKD guidelines; and formal self-improvement programs for the family physician, nephrologist, and CKD clinic. These efforts work to support improvement strategies and handle any problems strategically. One member of the CKD team would address quality improvement and patient safety, involving issues like prescription management, secure medical records, and incident reporting [9]. With different team members each providing their own services, it is essential to ensure effective communication and hand-off of care. Ineffective communication is often a contributing factor in medical errors and patient harm [10]. To address this problem, service agreements between the CKD clinic and family physician would explicitly state each professional's responsibilities in the different aspects of Paul's care. The CKD clinic also incorporates incentives to encourage excellent care. For example, after meeting with his dietician, Paul is particularly impressed with his ability to take into consideration the foods he normally eats. On his way out, he nominates his dietician for "Healthcare Provider of the Month"-an initiative started by the CKD clinic to encourage all team members to provide excellent quality care.

\section{Decision Support}

In Paul's case, decision support would involve embedding evidence-based CKD guidelines into his management, integrating his specialists and primary care, and proving a platform for his doctors to share important information with him. For example, between follow-up visits, Paul comes to your family practice with a urinary tract infection (UTI). You would not normally treat asymptomatic UTIs; however, PKD puts Paul at risk for recurrent UTIs and you are unsure about prescribing antibiotics. Based on the service agreement between you and Paul's nephrologist, you send him an email inquiring about the situation. Within hours, you receive a reply from the nephrologist, who, being fully aware of Paul's medical history, accurately advises you to prescribe antibiotics and provides you with evidence-based research on the subject. You phone Paul to inform him that he should take antibiotics and electronically send a prescription to his local pharmacy.

\section{Clinical Information Systems}

The CKD clinic utilizes a unique clinical information system similar to the National Health Services' Renal PatientView [11]. This information system is accessible by Paul, the CKD clinic, and his family physician. It includes basic details about Paul's diagnosis, treatment, and test results. Paul can login to the system, enter his weight and blood pressure regularly, and monitor his health performance. He can create lists of topics to discuss with his team and automatically receives email reminders about upcoming appointments. This system is effective in facilitating individ- 


\section{Commentary}

The Chronic Care Model

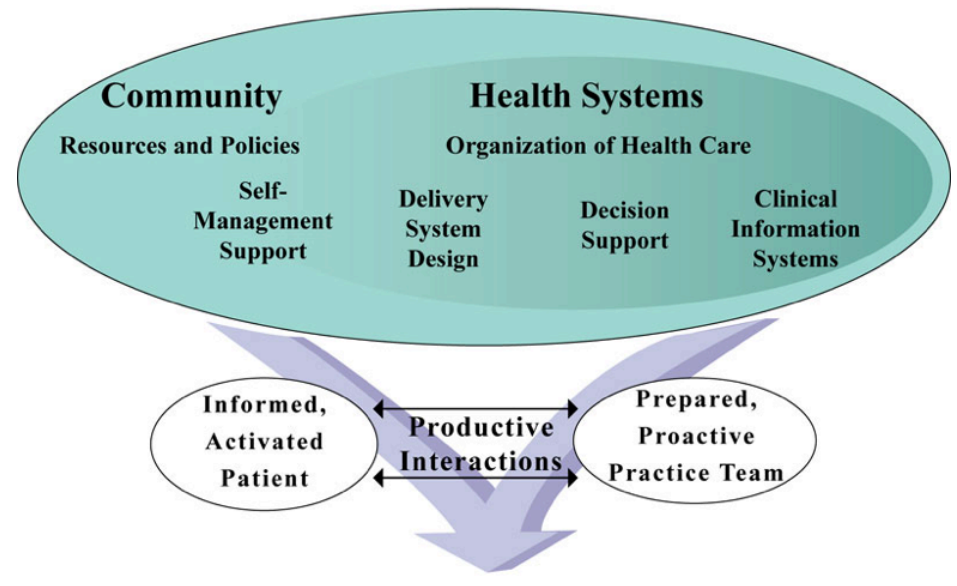

Improved Outcomes

Figure 1 illustrates the different components of Wagner's Chronic Care Model and how they are used to facilitate productive interactions between the patient and healthcare team to improve outcomes.

The chronic care model [Internet]. Seattle: Improving Chronic Illness Care; c2006-2014 [cited 2014 May 11] Available from: http://www.improvingchroniccare.org/index.php?p=The_Chronic_Care_Model\&s=2

ual patient care planning. For example, at an appointment with his dietician, Paul wonders if he can eat more protein. On the system, they examine Paul's blood work and health status over the past year. Paul is clinically stable and has been compliant to diets in the past. After a brief conference with the nephrologist, the dietician is able to loosen Paul's protein restrictions and monitor for any changes in his health status online.

\section{COMMUNITY}

\section{Resources and Policies}

Paul has been struggling with his diagnosis and feels guilty that his children are at risk for PKD. Paul's counsellor believes that he would benefit from an online community support group for patients with PKD and gives him information to set up an account. Using this online forum, Paul slowly comes to terms with his diagnosis and he is able to better discuss his mental health concerns with his counsellor. Using the online community, Paul works with his counsellor to advocate for better mental health awareness in his community and begins a support group for dealing with genetic disease.

At another visit, Paul mentions that he would like to add swimming to his exercise routine but cannot afford a full gym membership. His social worker is aware of the many community resources available and arranges a low-cost aquatic pass at the community centre.

\section{Self-Management Support}

As CKD does not typically display symptoms until an advanced stage, involving patients in their own management can be a challenge [8]. Early interdisciplinary team involvement fosters selfmanagement and Paul is reminded of his important role on the team at every appointment. At each yearly assessment, Paul receives a report card on the current state of his overall health, which he uses as motivation to remain an active and informed patient.

As Paul's kidney function worsens, he will eventually require renal replacement therapy (RRT). Since only $20 \%$ of CKD patients qualify for transplant [1], the clinic has an extensive pre-dialysis education program, including talks from dialysis patients, group discussion sessions, and visits to dialysis units. This program is designed to reduce the probability of emergency dialysis and hospitalization to lower medical costs [2], and it helps Paul remain an active member when making decisions about his future care.

\section{CONCLUSION}

The Chronic Care Model (CCM) provides an effective model to manage CKD and can be applied to other chronic medical conditions. Utilizing all six elements of the CCM allows for productive interactions between Paul and his care team, as illustrated in Figure 1. Through self-management support and multidisciplinary care, Paul is given the information to confidently and effectively make decisions about his health [5]. By designing an organized health system with an effective clinical information system and decision support, Paul's health care providers always have access to his information and knowledge about the best evidence for care [5]. Combining the informed, active patient with the prepared practice team allows for Paul to set goals with his team members and improve his clinical outcomes.

\section{REFERENCES}

1. Klostranec JM, Kolin DL, editors. Toronto Notes: A comprehensive medical reference \& review for MCCQE I \& USMLE II. 28th ed. Toronto, ON: Type \& Graphics Inc; 2012. NP21-23 p.

2. Stevens P. Models of chronic kidney disease care and initiation of dialysis. Presented at: Kent Kidney Care Centre, East Kent Hospitals, UK. PowerPoint presentation available from: http://www.kdigo.org/meetings_events/pdf/ novel_tech/Paul\%20Stevens.pdf

3. Barr VJ, Robinson S, Marin-Link B, Underhill L, Dotts A, Ravensdale D, et al. The expanded chronic care model: An integration of concepts and strategies from population health promotion and the chronic care model. Hospital Quarterly. 2003;7(1):73-83.

4. The chronic care model [Internet]. Seattle: Improving Chronic Illness Care; c2006-2015 [cited 2015 Apr 7]. Available from: http://www.improvingchroniccare.org/index.php?p=The_Chronic_Care_Model\&s=2

5. Improving chronic illness care. Does the chronic care model work? Presented at: Group Health's MacColl Institute. PowerPoint presentation available from: http://www.improvingchroniccare.org/downloads/2007_chronic_ care_model.ppt

6. Narva A, Briggs $M$. The national kidney disease education program: improving understanding, detection, and management of CKD. American Journal of Kidney Diseases. 2009; 53(3) Supplement 3: S115-S120. 
7. Ostbye T, Yamall KS, Krause KM, Pollak KI, Gradison M, Michener JL. Is there time for management of patients with chronic diseases in primary care? Ann Fam Med. 2005 May;3(3):209-214.

8. Poulos RK, Antonsen JE. Optimizing chronic kidney disease care: The primary-specialty care interface. BC Medical Journal. 2005;47(6):300-304.

9. Levitt C, Hilts L. Quality book of tools. Hamilton: McMaster Innovation Press; 2010.

10. Victorian Government Department of Health. Promoting effective communication among healthcare professionals to improve patient safety and quality of care. Melbourne: Victorian Quality Council; 2010.

11. Renal PatientView [Internet]. NHS; c2015 [cited 2015 Apr 7]. Available from: https://www.patientview.org/index.do 